\title{
Development of an air quality management framework for municipal government
}

\author{
J. C. Engelbrecht ${ }^{1 \star}$ and Van der Walt I. J. ${ }^{2}$ \\ ${ }^{1}$ Department of Environmental Health, Faculty of Science, Tshwane University of Technology, South Africa. \\ ${ }^{2}$ School of Environmental Sciences and Development, North West University, South Africa.
}

Accepted 23 August, 2012

\begin{abstract}
Air quality problems have been an inescapable partner of global economic development, and such problems have prevailed since the industrial age. After the democratisation of South Africa in 1994, the government embarked on a law reforming process to bring all the laws of the country in line with the new constitution of South Africa. This process included air quality legislation. Air quality management in South Africa has undergone drastic changes with the implementation of the National Environmental: Air Quality Act (Act 39 of 2004). In the previous dispensation, the Air Pollution Prevention Act (1965), emphasised point-source control, but the new act shifted the emphasis from point-source control to reactively protecting the receiving environment. In keeping with the new approach, municipalities are now required to compile, implement and maintain air quality management plans. Although, this is an explicit requirement of the Act, no guidelines exist for regulating bodies regarding the content of such plans. In this paper, a framework for generic air quality management plans for municipalities is proposed. This framework was compiled using information gained during a literature study of two countries where the implementation of air quality management plans has brought about an improvement in air quality, as well as two other countries where despite implementation of such plans, air quality has deteriorated. The information gained from the literature study was used to compile questionnaires that were distributed to all metropolitan councils and district municipalities $(N=54)$ in South Africa. To obtain a comprehensive, contextualised view on the issue, industries $(N=1290)$ were also included in the study. The main contribution of this study was the compilation of a framework for a generic air quality management plan to be used by municipal authorities. Due to the fact that lack of training has been identified as a critical gap in the successful implementation and maintenance of an air quality management plan, this study also makes a significant contribution to the identification of generic training outcomes.
\end{abstract}

Key words: Air quality management plans, air quality, municipality, local authorities, local government, framework, training outcomes.

\section{INTRODUCTION}

Management of air quality, to protect human health and the environment, is a major challenge facing countries in Africa. National and local authorities in Africa recognise the need to improve or maintain the quality of air to protect human health as well as the environment. Local, national, and regional authorities need to develop the appropriate capacity and capabilities for air quality

\footnotetext{
*Corresponding author. E-mail: engelbrechtjc@tut.ac.za.
}

management in order to set air quality and emission standards and implement air pollution control and monitoring strategies (Van Teinhoven and Simukanga, 2004). A wide variety of energy sources is used to meet Africa's energy needs: coal, fuel oil, kerosene, jet fuel, liquefied petroleum gas (LPG), gasoline, ethanol, fuel wood, charcoal, dung, biogas, and hydropower (Lungu and Mtawale, 2002). In Southern Africa, the SAFARI (2000) experiment has demonstrated that regional air quality is mostly determined by emissions from biogenetic processes, biomass (vegetation fires and domestic fuel 
wood), and industrial activity. It is evident that air pollution sources in Africa varied, ranging from local indoor coal fires affecting the health of a family, to national emissions of greenhouse gases that will impact on the global climate. Matooane and Mahema (2005) reported that apart from localised air pollution sources in each country, studies have shown transboundary air pollution between various countries in the Southern African region, as a result of the unique atmospheric circulation which leads to a phenomenon known as Southern African anticyclone gyre.

Tyson et al. (1996) reported that this gyre is ultimately responsible for the long range transport of pollutants to locations thousands of kilometres away from the source of pollution. Evidence shows that significant transport of air pollution from natural and anthropogenic sources from as far as the Democratic Republic of the Congo to the Indian Ocean are found, off the coast of South Africa and Mozambique (Annegarn et al., 2002).

As far as environmental management is concerned, the National Environmental Management Act, South Africa (NEMA) (1998a), was promulgated in 1998 to provide framework legislation for environmental governance in South Africa. This highly progressive legislation translates the environmental rights and responsibilities contained in the constitutions into legal provisions. NEMA provides an overall framework for general law reform in the environmental management field and provides the authority for environmental management to take place in a more pro-active, co-operative, and conciliatory manner.

During the course of 1999, the National Department of Environmental Affairs and Tourism (DEAT) initiated an environmental law reform process. Whilst NEMA provides the broad legislative framework for environmental governance in South Africa, details on substantive matters of environmental management such as biodiversity, air quality and waste management require dedicated legislation. As far as brown environmental issues (not direct conservation) are concerned (such as air quality management), the Integrated Pollution and Waste Management White Paper, 2002 (IP\&WM), South Africa (2000a), marked the starting point for the development of more specific policies, programmes and legislation in this area, including the National Air Quality Management Programme (NAQMP), South Africa (2005a), the National Waste Management Strategy and new legislation in the area of air quality and waste management.

As one of the key outputs of the law reform project, the National Environmental Management: Air Quality Act (NEM: AQA), no 39 of 2004 was gazetted on 24 February, 2005 (South Africa, 2004). It provides reasonable measures to prevent pollution, ecological degradation and to secure ecologically sustainable development, while promoting justifiable economic and social development (South Africa, 2005b).

According to section 156(1) of the Constitution of South Africa, South Africa (1996), a municipality has the executive authority in respect of air pollution, and has the right to administer the local government regulations listed in Part B of Schedule 4 of the Constitution that deals with air pollution. As per section 15(1) of NEM:AQA, metros and district municipalities are required to submit Air Quality Management Plans (AQMP) as part of their Integrated Development Plan (IDP) requirements and to report on an annual basis on the implementation status of their plans. As far as can be established, most of the metros and a few of the district municipalities progressed adequately towards establishing AQMPs. Scott (2004) reported that the management of air quality has become a high priority at local, national and international levels. Air quality management initiatives can be either proactive or reactive. In most cases air quality management programmes are reactive and are only initiated after ambient air pollution concentrations reach unacceptable levels.

Scorgie and Malan (2002) report that co-operative governance may take the form of industrial representation on environmental monitoring committees, the signing of voluntary agreements and the development and implementation of comprehensive air quality management plans. Such plans could be used to promote pollution reduction, impact quantification and management, access to information and/or local community liaison. They also suggest the following elements to be an integral part to effective an air quality management plan within the industrial and mining operations:

1) Baseline assessment

2) Mechanism for consultation with authorities as well as interested and affected parties

3) Source and receptor-based performance indicators and associated targets

4) Source and ambient air quality monitoring

5) Air pollution mitigation strategy

6) Record-keeping and documentation procedure

7) Financial provision

\section{Aim and objectives}

The general aim of this study was to develop a framework for a generic AQMP guideline document for the third (municipal) tier of government. The input from heavy industry formed an integral part of the study. The reason is that municipal AQMPs need to include the needs of industry and industry needs to implement actions of the plans approved by municipalities. The study is divided into the following four objectives.

\section{Objective 1: Development of an intervention model based on information gathered from key role players using questionnaires}

The identified key role players consisted of the 
municipalities (Metros and District Municipalities) as well as heavy industries.

Municipal (District/Metro): In terms of NEM:AQA, section 15(2), all municipalities are required to include an AQMP as part of their IDP in terms of Chapter 5 of the South Africa (2000b). No guidelines exist at present on how municipalities should compile such AQMPs. Their knowledge, opinion and understanding have been evaluated. The total population of metros and district municipalities in the Republic of South Africa (RSA) (N = 54) was included in the study.

Heavy industry: The population that has been surveyed is defined as the industries that are classified in terms of NEM:AQA is a listed activity (heavy industry) that is licensed by the DEAT (now DWAE). Two national databases exist for such industries. Due to the fact that the post-1996 database is incomplete and contains only the emission licence numbers and industry names, the database has been harmonised with the database prior to 1996. Any usable data from both lists $(N=1290)$ has been included as part of the population.

\section{Objective 2: Propose a framework for AQMP guidelines}

The purpose of this objective was to propose AQMP framework guidelines (that included input from heavy industry) for municipalities. It was assumed that if proper AQMPs are implemented and functions adequately, the air quality in that area where the AQMPs are developed for will improve over a period of time.

\section{Objective 3: Gap analysis for developed AQMP frameworks}

The purpose of this objective was to optimise the developed framework(s) according to AQMP guidelines. Possible gaps were identified by requesting important role-players to criticize the developed framework. Their recommendations were used to revise existing frameworks to comply with the requirements on NEM: AQA.

\section{Objective 4: Testing of hypothesis}

The revised framework was proposed as an intervention to important role-players in air quality management in South Africa and internationally. Many suggestions were used to further refine the proposed framework.

\section{MATERIALS AND METHODS}

In this study, when drafting the contents of the questionnaires for the municipalities and the industries, respectively, the minimum requirements as laid down for AQMPs in section 16(1) of the NEM:AQA were used. Details of other roles and responsibilities as contained in the NEM:AQA were also included in the questionnaires.

An international literature survey and questionnaires to municipalities and industries were used as methods to collect data.

\section{International literature survey}

A literature survey on the status quo of AQMPs in five countries was conducted to provide the basis for the compilation of the questionnaires used for the survey. National government has introduced local air quality management and its strategic framework for air pollution control in the context of a national air quality strategy. According to Vanderberg (2004), the implementation of management programmes has resulted in significant reductions in air pollutant emissions from stationary. Although, China's national environmental protection authorities generated hundreds of directives and guidance documents in the past two decades, implementation of environmental policy has always been largely a local matter, influenced by financial, institutional and political considerations (Florig et al., 2002). The Metropolitan Commission, responsible for the management of Mexico City has, since 1986, initiated and implemented various programmes to reduce the level of air pollution in the city. Garza (1996), however, confirms that despite of the noteworthy efforts, the end results have been far from satisfactory.

A study on the status quo of AQMPs in the RSA was conducted to conclude the literature study. Four AQMPs from the Metropolitan Councils of Tshwane (Tshwane Metropolitan Municipality, 2012), Joburg (City of Joburg, 2011), Ekurhuleni (Ekurhuleni Metropolitan Municipality, 2012) and Cape Town (City of Cape Town, 2011), respectively were assessed. Table 1 represents a summary of the critical elements of AQMPs as well as which of these critical elements are present in the AQMPs of the UK, USA, RSA, China and Mexico.

It is known that the air quality of China (Watts, 2005) and Mexico (Garza, 1996) is poor when compared to UK (Longhurst et al., 2000) and USA (Vanderberg, 2004). Therefore, elements which are found in AQMP's of both the UK and the USA, but which are absent from AQMP's of China and/or Mexico could therefore be regarded as imperative to ensure air quality improvement.

These success factors need to receive priority attention in the South African air quality management planning in future, while not negating other elements identified in Table 1, which are off course all important for effective air quality management. Table 2 provides a summary of the reasons for air quality management planning in the countries investigated not achieving positive results. The blank spaces (-) in Table 2 indicate that no specific information was present in the literature survey to conclude that it was seen as a problem.

\section{Drafting of questionnaires}

The critical elements of the AQMPs as identified in Tables 1 and 2 were included in the respective questionnaires. Table 3 summarises the sections covered in each questionnaire.

\section{Selection of populations}

Industry: Although, it is not a legal requirement for industries to submit AQMPs, they are an integral part of air quality management in their respective municipal areas due to their contributions to air pollution in a specific air shed. 
Table 1. Comparison of critical elements of AQMPs of the UK, USA, RSA, China.

\begin{tabular}{lccccc}
\hline Element & UK & USA & RSA & China & Mexico \\
\hline Air quality goals and objectives & $\sqrt{ }$ & - & $\sqrt{ }$ & - & $\sqrt{ }$ \\
Source inventories and emission quantification & $\sqrt{ }$ & - & $\sqrt{ }$ & $\sqrt{ }$ & - \\
Air quality monitoring & $\sqrt{ }$ & $\sqrt{ }$ & - & - & $\sqrt{ }$ \\
Air quality standards and guidelines & $\sqrt{ }$ & $\sqrt{ }$ & $\sqrt{ }$ & - & $\sqrt{ }$ \\
Simulation (dispersion) modeling & $\sqrt{ }$ & $\sqrt{ }$ & $\sqrt{ }$ & - & - \\
Public information and dissemination & $\sqrt{ }$ & $\sqrt{ }$ & - & - & - \\
Air quality alert & $\sqrt{ }$ & - & - & - & - \\
Planning and air quality management & $\sqrt{ }$ & $\sqrt{ }$ & - & - & - \\
Enforcement programme & - & $\sqrt{ }$ & - & $\sqrt{ }$ & $\sqrt{ }$ \\
Source control (national and international) & - & $\sqrt{ }$ & $\sqrt{ }$ & - & - \\
Staffing, funding and authority confirmation & - & $\sqrt{ }$ & $\sqrt{ }$ & - & - \\
Plan revision process & - & $\sqrt{ }$ & $\sqrt{ }$ & - & - \\
Energy conservation & - & - & - & $\sqrt{ }$ & - \\
\hline
\end{tabular}

Table 2. Comparison of reasons for failure of AQMPs.

\begin{tabular}{lccccc}
\hline Element & China & Mexico & UK & USA & RSA \\
\hline Political impracticability & $\sqrt{ }$ & - & - & - & $\sqrt{ }$ \\
Legislative and institutional barriers & $\sqrt{ }$ & - & $\sqrt{ }$ & $\sqrt{ }$ & - \\
Perception barriers & $\sqrt{ }$ & $\sqrt{ }$ & - & - & - \\
Local analytical / technical capability & $\sqrt{ }$ & $\sqrt{ }$ & - & - & - \\
Limited rule of law & $\sqrt{ }$ & $\sqrt{ }$ & - & - & - \\
Reactive control & - & $\sqrt{ }$ & - & - & $\sqrt{ }$ \\
Absence of public participation & $\sqrt{ }$ & $\sqrt{ }$ & - & - & $\sqrt{ }$ \\
Management of point sources only & $\sqrt{ }$ & $\sqrt{ }$ & - & - & - \\
Absence of prioritisation & - & $\sqrt{ }$ & - & - & $\sqrt{ }$ \\
Air quality standards not met & $\sqrt{ }$ & $\sqrt{ }$ & $\sqrt{ }$ & $\sqrt{ }$ & $\sqrt{ }$ \\
\hline
\end{tabular}

Table 3. Critical elements covered in questionnaire.

\begin{tabular}{lcc}
\hline Section & Municipal & Industry \\
\hline Geographical information & $\sqrt{ }$ & $\sqrt{ }$ \\
General (air quality infrastructure) & $\sqrt{ }$ & $\sqrt{ }$ \\
Air quality management policy and framework & $\sqrt{ }$ & - \\
Air quality management plan & $\sqrt{ }$ & $\sqrt{ }$ \\
Capacity & $\sqrt{ }$ & $\sqrt{ }$ \\
Air quality monitoring & $\sqrt{ }$ & $\sqrt{ }$ \\
\hline
\end{tabular}

Municipal government: District municipality and metro level of local government (AQMPs are the responsibility of aforesaid in terms of NEM:AQA) have been included in the study. The questionnaires were sent to the Municipal manager who had to delegate it to the officer responsible for air quality management. If such an officer was not employed at the metro/district municipality the questionnaire made provision for identification of an official to complete the questionnaire. The total population $(N=54)$ surveyed included six metropolitan municipalities and 48 district municipalities.

Literature survey: The literature study formed part of the research objective which was to conduct an international and national survey successes and failures in the implementation of AQMPs.

Questionnaires-pre-testing: Questionnaires were sent to knowledgeable persons $(n=7)$ that did not form part of the study population, for evaluation. Comments received were incorporated into the questionnaires, where applicable.

Questionnaires to municipalities: A structured questionnaire was sent to the district municipalities and metros.

Questionnaires to Industries: A structured questionnaire was sent to the employee(s) responsible for air quality management at each industry. Although, industries are not required to submit AQMPs in 


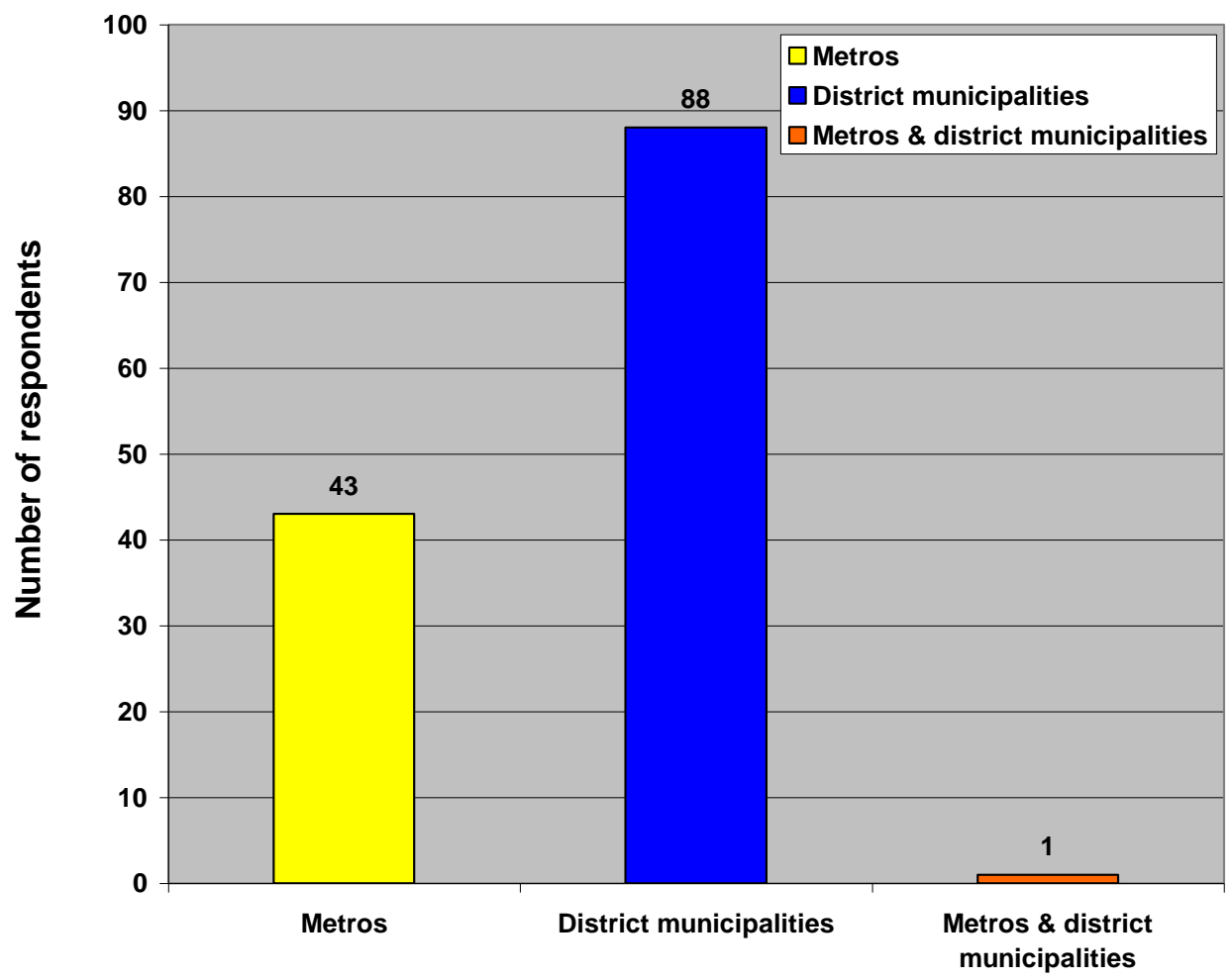

Figure 1. Location of industries within metros and district municipalities $(n=132)$.

terms of the NEM:AQA, the industries' applicable knowledge, attitudes and inputs were considered when drafting the AQMP guidelines. The total population of heavy industries was included in the study. It was decided against sampling, because opinions of industries are important due to the fact that they are an important role-player in generating air pollution.

\section{Testing of developed framework}

The hypothesis that includes the development of the generic framework as well as its possible implementation was tested by using e-mail correspondence. Role-players included representatives from professional associations, international academic institutions, scientific councils and industries that were not part of the data-acquisition.

\section{Data analysis}

Raw data from each of the questionnaires were coded using the Microsoft Excel software program. The coded data were then transferred and imported into the SAS statistics programme. The SAS output included frequencies of responses from municipal and industry questionnaires. The frequency tables were used to process the results.

\section{Ethics}

Whenever individuals were asked to complete questionnaires in their personal capacity, consent was always sought to use the data in the research. This research project was approved by the Ethics Committee of the Institution where the research was conducted.

\section{RESULTS}

The presentation of results relates to questionnaire responses to yes/no statements and rated statements in the form of a Likert scale of one to four (1=Agree, $2=$ Strongly agree, $3=$ Disagree and $4=$ Strongly disagree). Answers provided by respondents to open-ended questions were integrated into the various sections, where applicable.

\section{Demographics of municipalities and industries}

The response rate for municipalities (metros and district municipalities) was $35 \%$. Only two metros, the eThekwini (Durban) and Joburg (Johannesburg) metros did not respond. The overall response rate for metros was $67 \%$, while the response rate of district municipalities was $31 \%$.

\section{Demographics of industries}

A total of 1,290 industries was included during the survey. The response rate was 10\% with $219(17 \%)$ questionnaires undelivered and returned to sender. Figure 1 reflects the location of industries in metros and district municipalities. Industries located in district municipalities accounted for $67 \%$ of the total. Only one percent of industries are located in both, for the same 


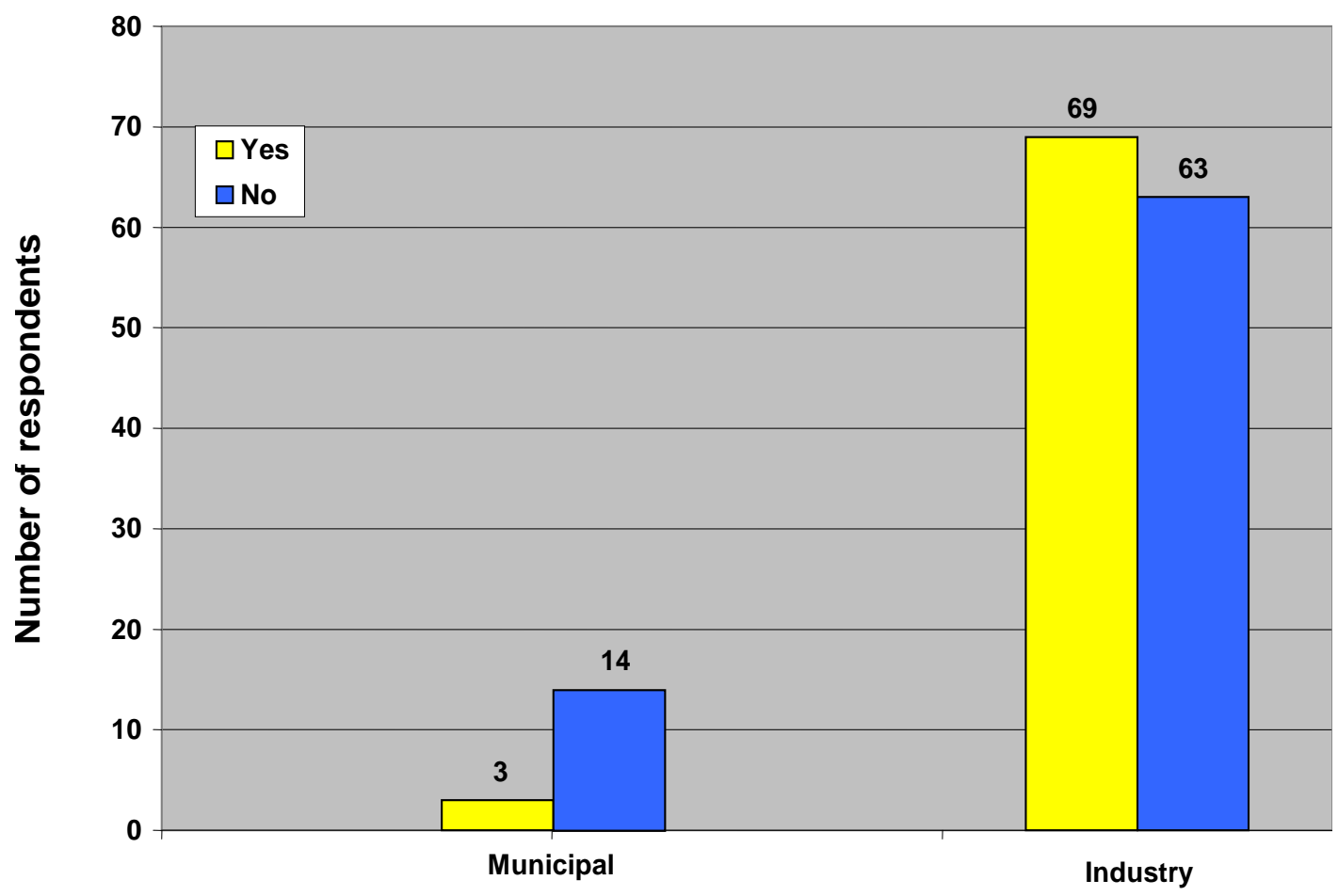

Figure 2. Appointment of air quality and air pollution control officers $(n=149)$.

reason as given earlier for geographical location per province. The reason for reporting on a population of 132 is due to the fact that one industry did not report its location.

\section{Human resources}

Figure 2 reflects the status of appointment of air quality officers for municipal and air pollution control officers for industry. The appointment of such officers at municipal level is a legal requirement in terms of NEM: AQA. For municipalities $18 \%$ indicated that they had appointed officers. $52 \%$ of industry reported that emissions control officers have been appointed. The implication is that it will be more effective to assign legal responsibilities to industries as required by Section $48(01)$ of the NEM: AQA because in the majority of situations there are already appointed officials.

\section{Air quality management infrastructure}

To assist with the effective development, implementation and maintenance of an AQMP, a dedicated air quality management section is imperative. Unique technical skills and competencies are needed for effective management. However, despite this being a legal requirement, the response from municipalities indicated that only $21 \%$ has a dedicated AQMP section.

\section{Air quality management capacity}

Technical capacity and competencies are especially needed to implement and maintain approved AQMPs. Figure 3 indicates that respondents from municipalities felt that $18 \%$ of the cases lacked the technical capacity to implement and maintain AQMPs. They were more confident about implementing and maintaining (18\%) than developing such plans (1\%). Industries reported that $67 \%$ of the case will be able to manage and implement an AQMP, while only $45 \%$ felt that they were competent to develop such a plan.

\section{Air quality management policies and framework}

International literature sources indicate that a vision, mission and objectives for air quality management form the basis for developing an AQMP (Beattie et al., 2001). Responses from municipalities, indicated that $28 \%$ did not have a vision, mission and objectives for air quality management

\section{Elements of an AQMP}

One of the main objectives of this study has been to establish a generic framework for the contents of AQMPs. Table 4 contains the responses from municipalities and industry on the elements suggested necessary 


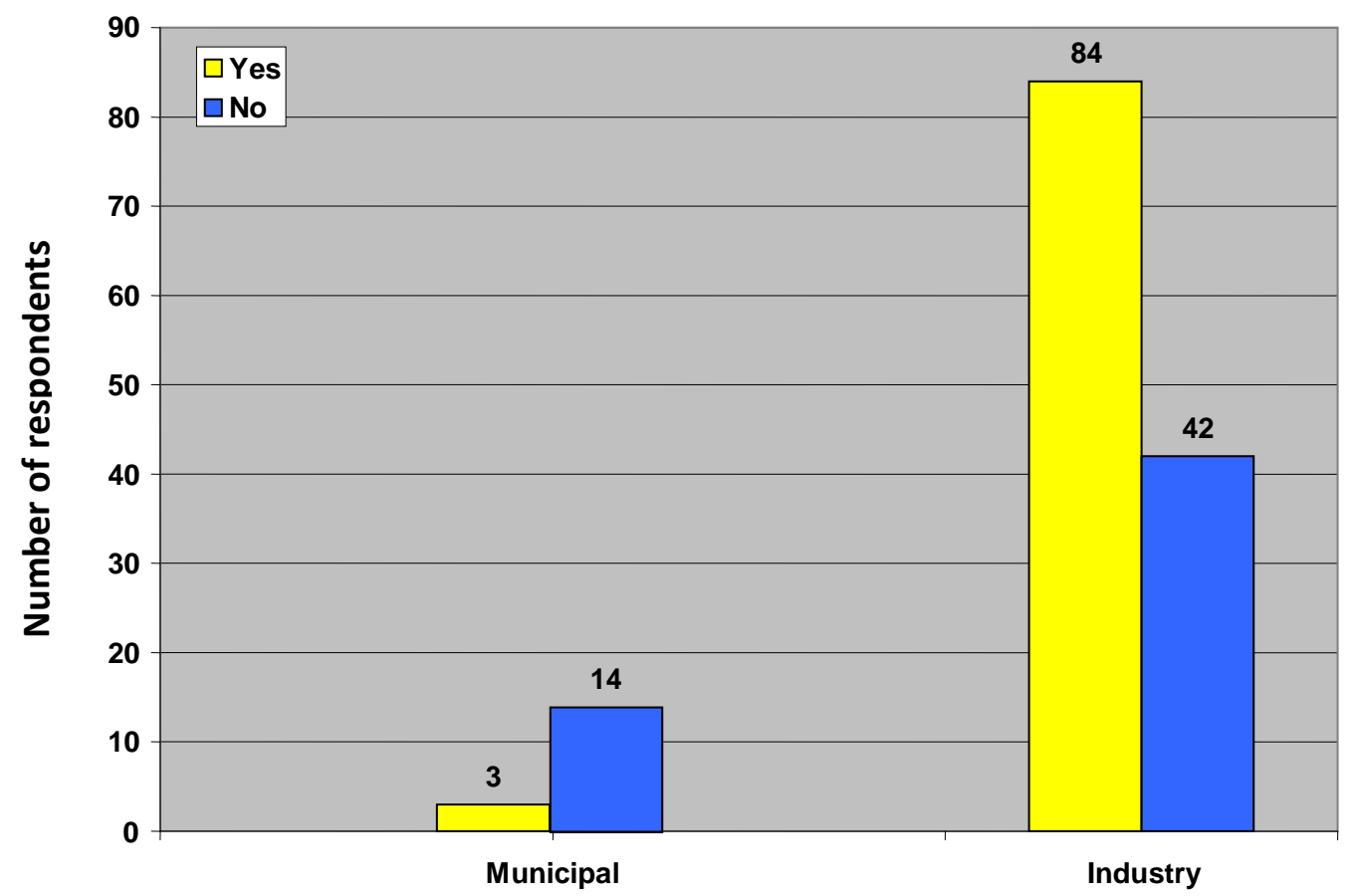

Figure 3. Technical capacity to implement and maintain AQMPs $(n=143)$.

Table 4. Elements of an AQMP.

\begin{tabular}{|c|c|c|c|c|}
\hline \multirow{2}{*}{ Element } & \multicolumn{2}{|c|}{ Municipalities } & \multicolumn{2}{|c|}{ Industry } \\
\hline & Agree (\%) & Disagree (\%) & Agree (\%) & Disagree (\%) \\
\hline Geographical information & 95 & 5 & 94 & 6 \\
\hline Policy framework for air quality management & 100 & 0 & 93 & 7 \\
\hline Air quality monitoring system & 100 & 0 & 96 & 4 \\
\hline Emission quantification and reduction programme & 100 & 0 & 96 & 4 \\
\hline Air quality management approval route & 100 & 0 & 91 & 9 \\
\hline Air quality management review process & 100 & 0 & 95 & 5 \\
\hline Capacity building process & 100 & 0 & 86 & 14 \\
\hline Financial implementation cost & 100 & 0 & 96 & 4 \\
\hline Setting of ambient air quality standards & 89 & 11 & 95 & 5 \\
\hline Research initiatives & 100 & 0 & 88 & 22 \\
\hline
\end{tabular}

for an effective AQMP. With the exception of two suggested elements (geographical information and setting of ambient air quality standards) on all the other elements, there was 100\% agreement by municipalities. From industry, the highest disagreement reported was on research initiatives, indicating that research initiatives are not considered to be a high priority element of an AQMP.

\section{AQMP data inputs}

The importance of data inputs as viewed by municipalities and industry, respectively are listed in Table 5 . Strong agreement was reported on all the suggested data inputs to populate an AQMP. The lowest agreement was reported by municipalities on contingency measures $(84 \%)$ and a long-term air quality management plan $(95 \%)$. Industry rated source inventory $(98 \%)$ and air quality monitoring data inputs (97\%) as most agreed upon. Commitment to international conventions and protocols as data inputs was rated lowest by industry (78\%).

\section{Community participation and involvement}

Various environmental laws, including the NEM:AQA require compulsory community participation processes to 
Table 5. Data inputs for an effective AQMP.

\begin{tabular}{lcccc}
\hline \multirow{2}{*}{ Data input } & \multicolumn{2}{c}{ Municipalities } & \multicolumn{2}{c}{ Industry } \\
\cline { 2 - 4 } & Agree (\%) & Disagree (\%) & Agree (\%) & Disagree (\%) \\
\hline Source information for all air pollution types & 100 & 0 & 95 & 5 \\
Meteorological monitoring data & 100 & 0 & 86 & 14 \\
Air quality monitoring data & 100 & 0 & 97 & 3 \\
Demographics and land use data & 100 & 0 & 83 & 17 \\
Priority pollutants to be controlled & 100 & 0 & 95 & 5 \\
Source inventory & 100 & 0 & 98 & 2 \\
Air pollution reduction strategies & 100 & 0 & 94 & 6 \\
Evaluation of strategies & 100 & 0 & 94 & 6 \\
How/when standards will be attained & 100 & 0 & - & - \\
Effect of growth and development & 100 & 0 & - & - \\
Contingency measures & 84 & 16 & - & - \\
A long range air quality management plan & 95 & 5 & - & - \\
Commitment to international conventions and protocols & 100 & 0 & 78 & 22 \\
Data on greenhouse pollutants & - & - & 89 & 11 \\
\hline
\end{tabular}

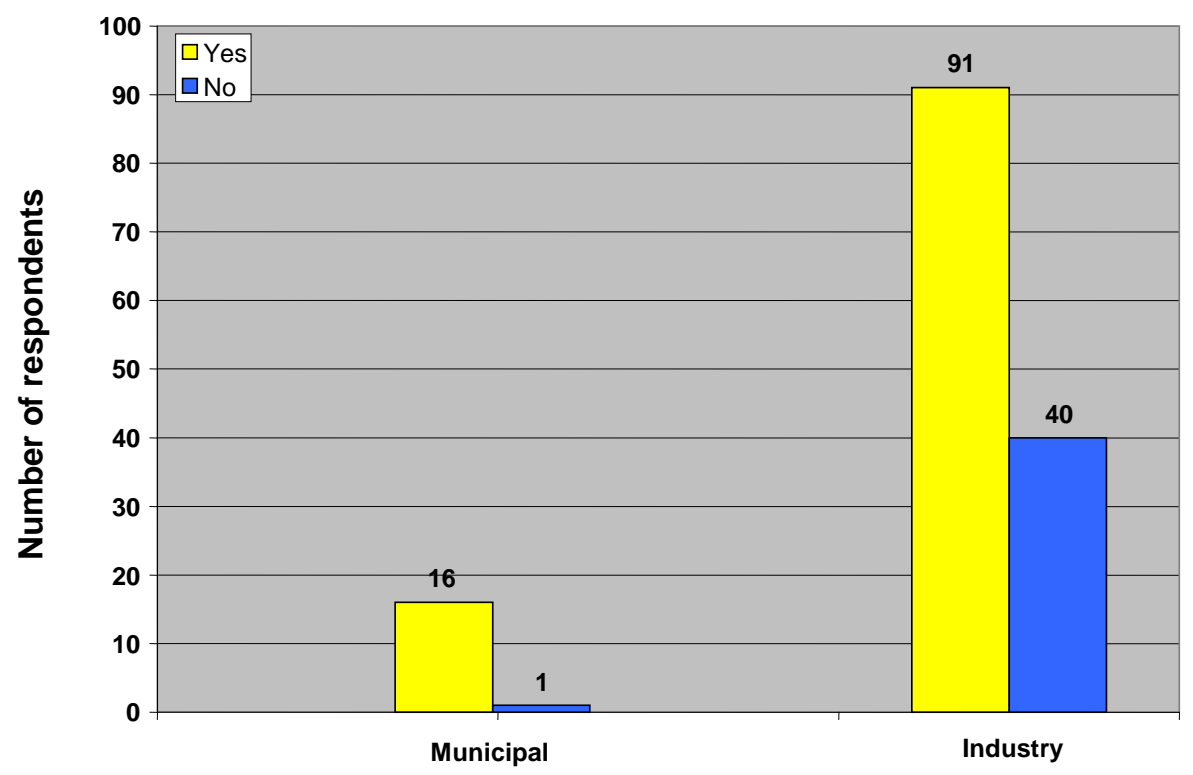

Figure 4. Community participation and involvement in developing an AQMP $(n=148)$.

be followed in environmental-decision making. Figure 4 summarises the opinion of municipalities as well as industry. Ninety four percent of the respondents representing municipalities highly value community participation in developing AQMPs.

\section{Training needs}

Responses to questions on the proposed contents of training outcomes to fill the gap between existing knowledge and skills, and what would be expected from officers, are summarised in Table 6 . With the exception of air pollution risk assessment (95\%), on all the other suggested training outcomes, there was a $100 \%$ agreement. Industry was least supportive of inclusion of air pollution modelling (83\%), followed by air pollution meteorology (86\%).

\section{Air quality monitoring}

Air quality monitoring has also been identified as a priority in the discussions that related to the elements of 
Table 6. Training needs outcomes.

\begin{tabular}{lcccc}
\hline \multirow{2}{*}{ Outcome } & \multicolumn{2}{c}{ Municipalities } & \multicolumn{2}{c}{ Industry } \\
\cline { 2 - 5 } & $\begin{array}{c}\text { Agree } \\
(\%)\end{array}$ & $\begin{array}{c}\text { Disagree } \\
(\%)\end{array}$ & $\begin{array}{c}\text { Agree } \\
(\%)\end{array}$ & $\begin{array}{c}\text { Disagree } \\
(\%)\end{array}$ \\
\hline Legislative framework & 100 & 0 & 96 & 4 \\
Air pollution and its characteristics & 100 & 0 & 96 & 4 \\
Engineering control & 100 & 0 & 92 & 8 \\
Atmospheric chemistry & 100 & 0 & 91 & 9 \\
Air pollution meteorology & 100 & 0 & 86 & 14 \\
Air pollution risk assessment & 95 & 5 & 95 & 5 \\
Air quality management principles & 100 & 0 & 97 & 3 \\
Air pollution modelling & 100 & 0 & 83 & 17 \\
Air pollution monitoring & 100 & 0 & - & - \\
Air pollution sources including identification and emission quantification & 100 & 0 & 96 & 4 \\
Air quality management planning & 100 & 0 & 94 & 6 \\
Stack monitoring & - & - & 90 & 10 \\
Ambient monitoring & - & - & 89 & 11 \\
\hline
\end{tabular}

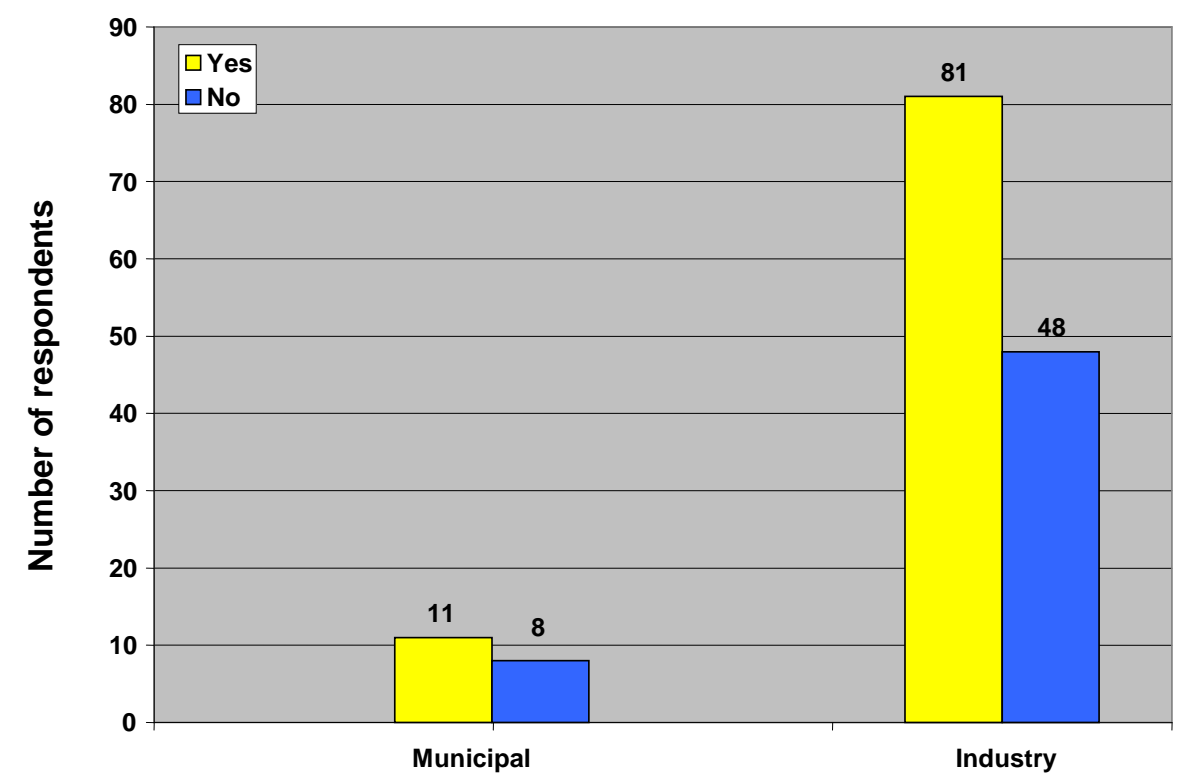

Figure 5. Air quality monitoring $(n=138)$.

an AQMP. It has been confirmed that an air quality monitoring system is a very important element of an AQMP. Figure 5 indicates that $58 \%$ of municipalities and $63 \%$ of industry confirmed that air quality monitoring was conducted in their areas.

\section{DEVELOPED GENERIC FRAMEWORK FOR AIR QUALITY MANAGEMENT PLANNING}

A generic AQMP framework has been developed from best practices extracted from an international literature survey conducted in four countries, as well as results of the questionnaires. Data inputs to populate an AQMP, as well as the benefits of an AQMP as outputs of an effective AQMP, have been compiled. Training outcomes needed to ensure that officers will be effective in compiling and managing AQMPs are part of the framework.

Figure 6 provides a summary of the elements necessary for a framework for an AQMP. For the elements of the framework to be effective, it needs to be populated with data. The generic data inputs for such a plan are also part of a generic framework. The benefits that will flow from an AQMP are indicated as an output of the AQMP. For the plan to be effective and efficient, it needs 
Generic data inputs

- Source information

- Meteorological monitoring

- Air quality monitoring data

- Demographics and land use

- Priority pollutants to be controlled

- Source inventory

- Reduction strategies

- Strategy evaluation

- Means of attaining standards

- Growth and development effects

- Contingency measures

- AQMP long range pollutants

- International commitments

- Greenhouse gas data

\begin{tabular}{|l|}
\hline \multicolumn{1}{|c|}{ Generic training } \\
Outcomes \\
- Legislation \\
- Air pollution characteristics \\
- Engineering control \\
- Atmospheric chemistry \\
- Meteorology \\
- Risk assessment \\
- Air quality management \\
- Air pollution modeling \\
- Air pollution monitoring \\
- Air pollution sources \\
- Air pollution quantification \\
- Air quality management planning \\
- Stack \& ambient monitoring \\
\hline
\end{tabular}

\begin{tabular}{|l|}
\hline \multicolumn{1}{|c|}{ Generic AQMP framework } \\
elements \\
- Geographical information \\
- Policy framework \\
- Air quality monitoring system \\
- Emission quantification \& reduction \\
- Air quality management approval route \\
- Air quality management review process \\
- Capacity development process \\
- Financial implementation cost \\
- Setting of ambient air quality standards \\
- Research initiatives \\
\hline
\end{tabular}

Generic benefit outputs of an AQMP
- Air quality levels achieved
- Clean and healthy environment established
- Negative impacts on health \& environment minimised
- Gegishouse gases reduced
- Relations with interested and affected parties improved

Figure 6. Generic framework for an AQMP indicating inputs and outputs.

to be managed by competent technical officers. Generic training outcomes have been identified as input into the development of officers responsible for the development, implementation and management of AQMPs.

\section{Gap analysis-framework for municipalities}

All the suggested elements for an AQMP framework were strongly supported by municipalities. The following is seen to be gaps in the present AQMPs that need to be addressed:

1) Due to no response from municipalities in the Limpopo and North West provinces, respectively, AQMP awareness needs to be focused on.

2) An $89 \%$ response from environmental health practitioners can indicate that training needs have to be 
focused on. Priority attention needs to be provided, because this grouping is seen as a priority presently responsible for AQM.

3) Appointment of air quality officers is seen as a major shortcoming; only $18 \%$ had such officers.

4) An AQM infrastructure needs to become available, therefore, it should be a priority; only $21 \%$ indicated that such infrastructure existed.

5) Lack of technical capacity has been identified as a major shortcoming; only $5 \%$ of municipalities were confident about their technical capacity.

6) Municipalities need to reorganise their budgets to include AQMP development, implementation and maintenance. This was identified as a major shortcoming, because $94 \%$ indicated that they were aware of constraints. Especially international donor organisations and the DEAT need to be targeted as sources of income.

7) Due to the fact that it is a legal requirement to have an approved AQMP, it is disturbing to note that $82 \%$ of municipalities reported that no plans were even in the process of being approved. Priority needs to be given to approval of a plan.

8) Municipalities were very receptive to the training outcomes for municipal officers. Due to the identification of a major gap as far as technical capacity is concerned, training needs to be treated as a matter of urgency. All the training outcomes suggested were fully supported with the exception of air quality risk assessment (95\%).

\section{CONCLUSION AND RECOMMENDATIONS}

Key results that flowed from this study can be summarised as follows:

1) The highest response rate came from Environmental Health Departments indicating their involvement and motivation to be part of AQM.

2) The appointment of air pollution control officers is very slow and needs urgent attention as it is a legal requirement.

3) Technical capacity is seriously lacking at municipal level. Financial constraints were highlighted by majority of respondents from municipalities, and needs to be addressed at national level (funding provider).

4) The most important contribution of this study, is however the fact that a generic air quality management framework can be applied, supported by generic data input, generic training outcomes to strengthen capacity as well as benefits derived from implemented frameworks.

\section{Contributions of the study}

The main contribution of this study is the formulation of a generic AQMP to be used by municipalities in compiling AQMPs required by the NEM:AQA. Due to the fact that training has been identified as a critical factor in the successful implementation and maintenance of an AQMP, this study makes an important contribution towards the identification of generic training outcomes to empower officers responsible for AQMPs. Due to the fact that the NEM: AQA is not clear on the detail of AQMPs, this study can form the basis for the development of national guidelines for AQMPs. Such a uniformed approach can assist especially national and provincial government with reports such as the state of the environment, because information in AQMPs is then reported uniformly. Important data representing the state of AQMPs including implementation are also now available as a management tool for the three tiers of government.

The main benefit of this study was that a framework for air quality management is available to municipalities that contribute to uniformity as well as proper guidance. The framework has also been included in guideline documents drafted by the National Department of Environmental Affairs. The acceptance level by municipalities of the framework was very high and all new and amended AQMPs were drafted according to the recommended framework.

\section{REFERENCES}

Annegarn HJ, Otter L, Swap RJ, Scholes RJ (2002). Southern Africa's ecosystem in a test-tube - A perspective on the Southern African Regional Science Initiative (SAFARI 2000). S. Afr. J. Sci. 98:111113.

Beattie Cl, Longhurst JWS, Woodfield NK (2001). Air quality management: evolution of policy and practice in the UK as exemplified by the experience of English local government. Atmos. Environ. 35:1479-1490.

City of Cape Town (2011). Air Quality Management Plan for the City of Cape Town. Report number AQM 20050823-001.

City of Joburg (2011). Air Quality Management Plan for the City of Johannesburg. Report number MTX/03/JHB-01e.

Ekurhuleni Metropolitan Municipality (2012). Air Quality Management Plan for the Ekurhuleni Metropolitan Municipality. Report number APP/04/EMM-02c.

Florig HK, Sun G, Song G (2002). Evolution of particulate regulation in China - prospects and challenges of exposure-based control. Chemosphere 49:1163-1174.

Garza J (1996). Uncontrolled air pollution in Mexico City. Cities 13(5):315-325

Longhurst JWS, Elsom DM, Power H (2000). Air quality management. Southampton USA: WIT Press pp. 40-42.

Lungu C, Mtawale C (2002). In: Sikazwe ON, Masialeti M, Simukanga S, Hicks WK. Proceedings of the Workshop on Impacts of Air Pollution in Southern Africa. 27 May. Lusaka, Zambia.

Matooane M, Mahema T (2005). Air Pollution Information network or Africa (APINA). Activities in South Africa. (National Association for Clean Air Conference, September 29, Cape Town, South Africa).

Safari (2000). (Available on http://safari.gecp.virginia.edu/index.as: pp. $2-4$.

Scorgie Y, Malan J (2002). Proactive air pollution prevention and air quality management - The responsibility of industry under the National Air Quality legislation. Clean Air J. 10(8):14-24.

Scott GM (2004). The determination of boundaries of the air sheds over Kwazulu-Natal-Preliminary investigations. (National Association for Clean Air Conference, October 4, Midrand, South Africa).

South Africa (1996). The Constitution of the Republic of South Africa as adopted by the Constitutional Assembly on 8 May 1996 and as amended on 11 October 1996. Pretoria: Government Printer pp.B34- 
B96.

South Africa (1998a). National Environmental Management Act, no. 107 of 1998. Government Gazette: 1540 (19519) Nov 27.

South Africa (2000a). Department of Environmental Affairs and Tourism. White Paper on Integrated Pollution and Waste Management for South Africa. Government Gazette March 17. 227(20978).

South Africa (2000b). Local Government: Municipal Systems Act, no. 32 of 2000. Government Gazette: 1187(21776), Nov. 20.

South Africa (2004). National Environment: Air Quality Act, no. 39 of 2004. Government Gazette, 476(27318) Feb. 24:1-57.

South Africa (2005a). Department of Environmental Affairs and Tourism. The National Air Quality Management Programme, output c.1. Air quality information review. Pretoria.

South Africa (2005b). Commencement of certain sections of the National Environmental Management: Air quality Act (Act no. 39 of 2004). Government Gazette GN 898 GG 280169 September 2005. Pretoria.
Tshwane Metropolitan Municipality (2012). Air Quality Management Plan for the City of Tshwane Metropolitan Municipality. Report number APP/05/CTMM-02 Rev 0.

Tyson PD, Garstang M, Swap R (1996). Large scale recirculation of air over Southern Africa. J. Appl. Meteorol. 35:2218-2236.

Van Teinhoven M, Simukanga S (2004). Strengthening the air quality management community in Africa - the role of the Air Pollution Information Network (APINA). (National Association for Clean Air Conference, 4 October, Midrand, South Africa).

Vanderberg JJ (2004). The role of air quality management programs in improving public health. A brief synopsis. J. Allergy Clin. Immunol. 115(2):334.

Watts J (2005). China: the air pollution capital of the world. Lancet 366(9499):1761-1762. 